\title{
Long-term effects of sediment-associated silver nanoparticles and silver nitrate on the deposit-feeding polychaete Capitella teleta
}

Nielsen, Maria Bille; Vavra, Janna; Palmqvist, Annemette; Forbes, Valery E.

Published in:

Aquatic Toxicology

Link to article, DOI:

10.1016/j.aquatox.2021.106046

Publication date:

2022

Document Version

Publisher's PDF, also known as Version of record

Link back to DTU Orbit

Citation (APA):

Nielsen, M. B., Vavra, J., Palmqvist, A., \& Forbes, V. E. (2022). Long-term effects of sediment-associated silver nanoparticles and silver nitrate on the deposit-feeding polychaete Capitella teleta. Aquatic Toxicology, 242, [106046]. https://doi.org/10.1016/j.aquatox.2021.106046

\section{General rights}

Copyright and moral rights for the publications made accessible in the public portal are retained by the authors and/or other copyright owners and it is a condition of accessing publications that users recognise and abide by the legal requirements associated with these rights.

- Users may download and print one copy of any publication from the public portal for the purpose of private study or research.

- You may not further distribute the material or use it for any profit-making activity or commercial gain

- You may freely distribute the URL identifying the publication in the public portal 


\title{
Long-term effects of sediment-associated silver nanoparticles and silver nitrate on the deposit-feeding polychaete Capitella teleta
}

\author{
Maria Bille Nielsen ${ }^{\mathrm{a}, *}$, Janna Vavra ${ }^{\mathrm{b}}$, Annemette Palmqvist ${ }^{\mathrm{c}}$, Valery E. Forbes ${ }^{\mathrm{d}}$ \\ ${ }^{a}$ Department of Environmental Engineering, Technical University of Denmark, 2800 Kgs. Lyngby, Denmark \\ ${ }^{\mathrm{b}}$ School of Biological Sciences, University of Nebraska-Lincoln, United States \\ ${ }^{\mathrm{c}}$ Department of Science and Environment, Roskilde University, Denmark \\ d Department of Ecology, Evolution and Behavior, University of Minnesota, United States
}

\section{A R T I C L E I N F O}

\section{Keywords:}

Deposit-feeder

Ecotoxicity

Long-term exposure

Sediment

Silver nanoparticles

Silver nitrate

\begin{abstract}
A B S T R A C T
Aquatic sediments are predicted to be an important sink for released silver nanoparticles (AgNPs). Knowing the long-term effects of AgNPs on benthic deposit-feeders is therefore an important step towards assessing their potential environmental risks. The aim of this study was to examine the effects on survival, growth and reproduction of the deposit-feeding polychaete Capitella teleta exposed for ten weeks to sediment-associated un-coated AgNPs or silver nitrate $\left(\mathrm{AgNO}_{3}\right)$. C. teleta exhibited tolerance towards exposure to both $\mathrm{AgNPs}$ and $\mathrm{AgNO}_{3}$. Significant effects were observed for percentage of pairs that reproduced as well as worm growth after eight weeks, but the effects did not show a clear concentration- or Ag type-dependent pattern. Further investigations of long-term effects of un-coated AgNPs in additional sediment-dwelling organisms are needed and should involve comparisons to coated AgNPs.
\end{abstract}

Silver is a widely used metal in many consumer products due to its antimicrobial properties (Hernández et al., 2021), and the emergence of nanotechnology has further expanded its uses as silver nanoparticles (AgNPs). Applications of AgNPs include e.g. clothing, detergents, food, paints and disinfection products (Hansen et al., 2020; Hansen et al., 2016; Gottschalk et al., 2015). Environmental concerns about the use of AgNPs have been raised due to release of the particles to the environment. Toxic effects have been reported in a range of organisms, such as fish (Zhao et al., 2019; Rajkumar et al., 2016), algae (Johari et al., 2018) and invertebrates (Luo et al., 2016; Ribeiro et al., 2015). Luo et al. (2016) observed negative effects on reproduction and survival of the invertebrate Caenorhabditis elegans when exposed to polyvinylpyrrolidone-coated AgNPs, and in Ribeiro et al. (2015), exposure to AgNPs (AgNM300K standard particles) was found to induce oxidative stress in the invertebrate Enchytraeus crypticus. Aquatic sediments have been identified as an important sink for AgNPs (Ramskov et al., 2015; Baun et al., 2008). Concentrations of AgNPs in sediments have been estimated to be in the range of $18.3-43.4 \mu \mathrm{g} / \mathrm{kg}$ in Europe (Sun et al., 2016) with yearly increases between 1.8 and $3.3 \mu \mathrm{g} / \mathrm{kg}$ (Sun et al., 2014). Gottschalk et al. (2015) reported AgNP concentrations in Danish marine sediments of $0-0.7 \mu \mathrm{g} / \mathrm{kg}$.

The marine polychaete Capitella teleta is an opportunistic sediment- dwelling deposit feeder, often inhabiting polluted and organically enriched environments (Blake et al., 2009; Ramskov et al., 2009; Selck et al., 1998). It lives buried in the upper few centimeters of the sediment in which it feeds on living and dead organic matter (Lopez and Levinton, 1987). In order to meet its nutritional needs, C. teleta ingests daily sediment quantities of up to 12 times its own body weight (Selck et al., 1998; Dai et al., 2012) and is therefore likely to be exposed to sediment-associated contaminants, such as AgNPs. The aim of this study was to investigate the effects on survival, growth and reproduction of long-term exposure (ten weeks) to sediment-associated AgNPs in C. teleta. To assess if potential effects were related to the nanoparticles (NPs) themselves or to release of $\mathrm{Ag}$ ions $\left(\mathrm{Ag}^{+}\right)$, exposure to $\mathrm{Ag}^{+}$was included as a treatment.

C. teleta worms were exposed to un-coated silver nanoparticles (AgNPs) or silver nitrate $\left(\mathrm{AgNO}_{3}\right)$ added to marine sediment collected from Munkholm, Isefjorden, Denmark. Un-coated AgNPs are environmentally relevant to test as nanoparticle coatings may be degraded or substituted with natural organic matter upon environmental exposure (Diegoli et al., 2008; Ellis et al., 2016). Three nominal sediment Ag concentrations were prepared for both AgNPs and $\mathrm{AgNO}_{3}: 1$ (low), 10 (medium) and 100 (high) $\mu \mathrm{g} \mathrm{Ag/g}$ dry weight sediment (dw sed), providing 7 treatment groups: AgNP-low, AgNP-medium, AgNP-high,

\footnotetext{
* Corresponding author.

E-mail address: mabini@env.dtu.dk (M.B. Nielsen).
} 


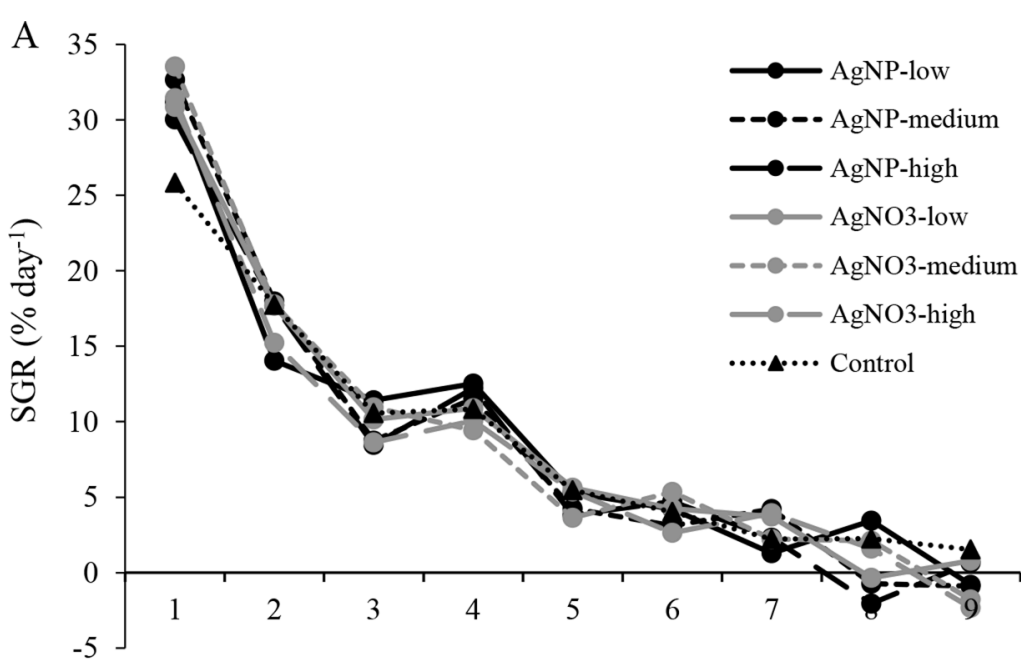

Time (weeks)
Fig. 1. A, Mean specific growth rates (SGR) of C. teleta during nine weeks of exposure to either un-coated silver nanoparticles (AgNPs) or silver nitrate $\left(\mathrm{AgNO}_{3}\right)$ added to sediment in nominal concentrations of 1 (low), 10 (medium) and 100 (high) $\mu \mathrm{g} \mathrm{Ag/g}$ dry weight sediment or to clean sediment (control), calculated as $\%$ change in body volume relative to time $\left(\%\right.$ day $\left.^{-1}\right)$, and $\mathrm{B}$, C. teleta final body volume $\left(\mathrm{mm}^{3}\right)$ after nine weeks of exposure (mean \pm SD). Different letters on bars indicate significant $(p \leq 0.05)$ difference between treatments.

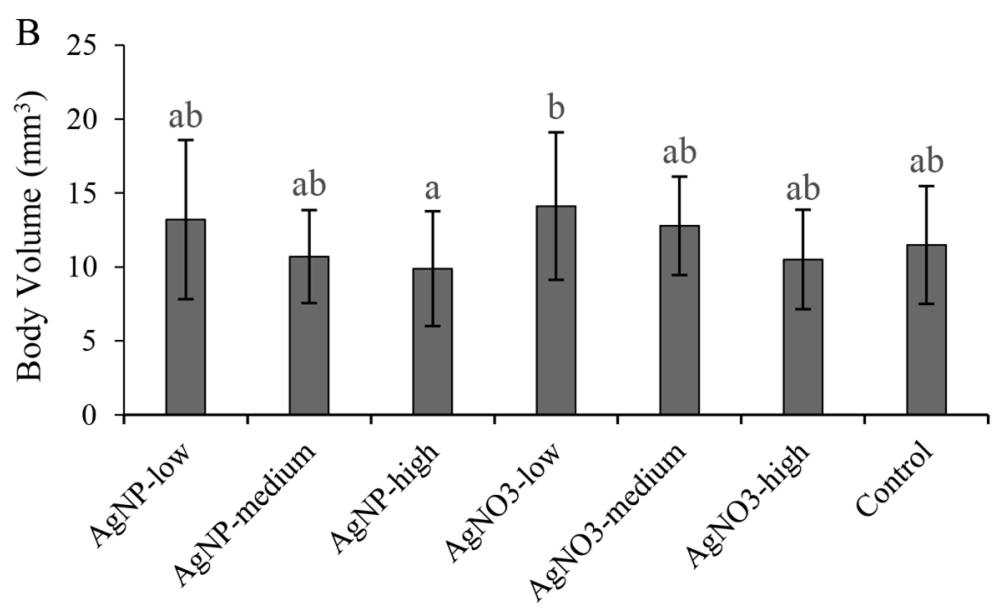

Treatment

$\mathrm{AgNO}_{3}$-low, $\mathrm{AgNO}_{3}$-medium, $\mathrm{AgNO}_{3}$-high and Control. The concentration range was selected as it covers both the lower end of the analytical detection limit as well as exceeds the estimated environmental sediment concentrations. Sediment was spiked according to the USEPA method for Slurry Spiking (US Environmental Protection Agency, 2001) with slight modifications. Ag concentrations were measured with inductively coupled plasma mass spectrometry (ICP-MS) and AgNP characterization included measurement of hydrodynamic diameter, size distribution, zeta potential, particle size and morphology. Dynamic light scattering (DLS) measurements and images taken using transmission electron microscopy (TEM) revealed roughly spherical and relatively unstable AgNPs with a mean primary particle size of $74.1 \mathrm{~nm}( \pm 25.4, n=66)$. C. teleta juveniles were 8,9 days old when the experiment was initiated, and for ten weeks worms were monitored for survival, growth and reproductive output. In Supplementary Material more details on experimental setup, sediment characteristics (Table S1), Ag analysis (Table S2) and AgNP characterization (Table S3 and Fig. S1) are provided.

Measured sediment Ag start concentrations were lower than nominal (approximately 3.5 to 11 times), and $\mathrm{Ag}$ concentrations were higher in sediments spiked with $\mathrm{AgNP}$ than $\mathrm{AgNO}_{3}$. The highest $\mathrm{Ag}$ concentrations were 28.8 and $16.2 \mu \mathrm{g} \mathrm{Ag} / \mathrm{g}$ dw sed for sediment spiked with AgNPs and $\mathrm{AgNO}_{3}$, respectively. One explanation of the lower Ag concentrations may be that Ag was lost to the extracted water upon sediment spiking, however, as Ag concentrations were not measured in overlying water or porewater, this is uncertain. In Ramskov et al. (2015), the concentration of $\mathrm{AgNPs}$ and $\mathrm{AgNO}_{3}$ was measured in both the sediment and the overlying water in a test system with $C$. teleta, and the results showed higher $\mathrm{Ag}$ concentrations in the overlying water in $\mathrm{AgNO}_{3}$ treatments $(25 \pm 19 \mu \mathrm{g} \mathrm{Ag} / \mathrm{L})$ compared to AgNP treatments $(<3 \mu \mathrm{g} \mathrm{Ag} / \mathrm{L})$. Zeta potential of the AgNP suspension in this study prior to sediment spiking was between -30 and $30 \mathrm{mV}$, indicating unstable particles that likely settled out of suspension (by adsorption to sediment particles or forming aggregates/agglomerates) to a higher extent than $\mathrm{AgNO}_{3}$. Despite the instability, TEM images revealed that at least some AgNPs were dispersed as single particles and therefore were probably available for uptake in C. teleta if adsorbed to sediment particles ingested by the worms.

After ten weeks of exposure to $\mathrm{AgNPs}$ and $\mathrm{AgNO}_{3}$, there was no effect of any treatment on survival, and almost all worms survived to the end of the experiment. Only minor effects on growth were observed (Fig. 1A). After eight weeks, growth rates of worms from the AgNP-high treatment were significantly lower than worms in the AgNP-low, $\mathrm{AgNO}_{3}$-medium and control treatments (Dwass-Steel-ChritchlowFligner, $p \leq 0.008$ ). After nine weeks, worm growth rates were significantly lower for worms in the $\mathrm{AgNO}_{3}$-high treatment compared to worms in the control (Dwass-Steel-Chritchlow-Fligner, $p=0.032$ ). Comparison of final body volumes of $C$. teleta after nine weeks of exposure (Fig. 1.B) showed that body volumes of $C$. teleta were significantly lower in the AgNP-high treatment than the $\mathrm{AgNO}_{3}$-low treatment 
Table 1

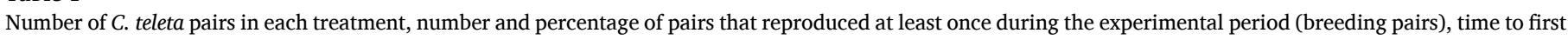

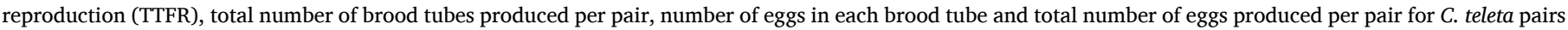

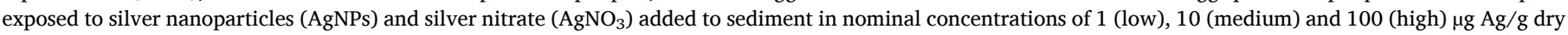
weight sediment or to clean sediment (control) for ten weeks. TTFR, brood tubes per pair, eggs per brood tube and eggs per pair are given as mean \pm SD.

\begin{tabular}{|c|c|c|c|c|c|c|c|}
\hline & AgNP-low & $\begin{array}{l}\text { AgNP- } \\
\text { medium }\end{array}$ & AgNP-high & $\mathrm{AgNO}_{3}$-low & $\begin{array}{l}\mathrm{AgNO}_{3-}^{-} \\
\text {medium }\end{array}$ & $\mathrm{AgNO}_{3}$-high & Control \\
\hline Number of pairs & 11 & 11 & 9 & 10 & 7 & 7 & 6 \\
\hline $\begin{array}{l}\text { Number of breeding pairs (and percentage out of total number } \\
\text { of pairs) }\end{array}$ & $5(45.5 \%)$ & $6(54.5 \%)$ & $5(55.6 \%)$ & $5(50.0 \%)$ & $1(14.3 \%)$ & $4(57.1 \%)$ & $\begin{array}{l}4 \\
(66.7 \%)\end{array}$ \\
\hline TTFR (weeks after start of experiment) & $6.4 \pm 0.5$ & $6.2 \pm 0.4$ & $7.2 \pm 1.6$ & $7.4 \pm 1.2$ & $8.0 \pm 0.0$ & $7.5 \pm 1.7$ & $6.8 \pm 0.8$ \\
\hline Brood tubes per pair & $1.5 \pm 1.8$ & $2.1 \pm 2.0$ & $1.8 \pm 1.9$ & $1.2 \pm 1.6$ & $0.1 \pm 0.3$ & $2.0 \pm 2.1$ & $2.2 \pm 2.0$ \\
\hline Eggs per brood tube & $201.4 \pm 84.9$ & $\begin{array}{l}186.0 \pm \\
50.4\end{array}$ & $159.5 \pm 51.6$ & $176.3 \pm 88.0$ & $455 \pm 0.0^{*}$ & $149.5 \pm 56.9$ & $\begin{array}{l}164 \pm \\
48.5\end{array}$ \\
\hline Eggs per pair & $\begin{array}{l}311.2 \pm \\
407.1\end{array}$ & $\begin{array}{l}389.0 \pm \\
369.2\end{array}$ & $\begin{array}{l}283.6 \pm \\
302.2\end{array}$ & $\begin{array}{l}211.5 \pm \\
249.2\end{array}$ & $65 \pm 159.2$ & $\begin{array}{l}292.3 \pm \\
312.8\end{array}$ & $\begin{array}{l}355.3 \pm \\
373.5\end{array}$ \\
\hline
\end{tabular}

* Only one pair bred in this treatment and they produced only one brood tube, explaining the lack of variation.

(Tukey, $p=0.014$ ).

All worms except for two reached sexual maturity during the third or fourth week of exposure. No significant differences were found in time to reach maturity among treatments (Kruskal-Wallis, $p=0.742$ ) and mean maturation time calculated from all worms (in weeks of exposure) was 3.4 weeks $( \pm 0.58, n=158)$. In all treatments there were cases of pairs that reproduced (breeding pairs) and pairs that did not. The highest percentage of breeding pairs was found in the control treatment with $66.6 \%$ (Table 1). Percentages of breeding pairs in AgNP-low, $\mathrm{AgNO}_{3}$-low and $\mathrm{AgNO}_{3}$-medium were found to be significantly lower than the percentage of breeding pairs in the control treatment (Chi-square, $p<$ 0.05). There were no effects of $\mathrm{AgNPs}_{\text {or }} \mathrm{AgNO}_{3}$ exposure on time to first reproduction, number of brood tubes or total numbers of eggs produced per pair. Visual observations of brood tubes, collected after 9 weeks of exposure, revealed close to 100 percent hatching success of eggs in all treatments. Our study showed a high within-treatment variation in reproductive endpoints, possibly caused by the circumstances under which the worms were paired and pairs were kept. In Ramskov and Forbes (2008) reproduction in C. teleta was investigated under different sediment organic matter (OM) concentrations. Under the highest $\mathrm{OM}$ concentration (3\%), which is lower than the OM concentration in the present study, C. teleta started reproducing approximately 2,3 weeks earlier than in this study, and at least $80 \%$ of the females reproduced. In Ramskov and Forbes (2008) juveniles were kept in groups of 20 prior to pairing, whereas in the present study, juveniles were kept individually. The lack of presence of other worms during development until sexual maturation may explain the delayed reproductive output. The numbers of eggs in each brood tube in Ramskov and Forbes (2008) were approximately $220( \pm 50)$ on average, which does not differ considerably from this study with an average number of eggs per brood tube of 177.10 ( \pm 72.23 ).

As is evident from the results, C. teleta showed tolerance to both AgNP and $\mathrm{AgNO}_{3}$ exposure with no effect on survival and only minimal effects on growth and reproduction during ten weeks of exposure. The effects did not show a clear concentration- or Ag type-dependent pattern, rendering the potential impacts of $\mathrm{AgNPs}$ and $\mathrm{AgNO}_{3}$ at the concentrations tested here uncertain. In previous studies by Ramskov et al. (2015) and Dai (2012), C. teleta also demonstrated tolerance to sediment-associated $\mathrm{Ag}$ exposure in the form of $\mathrm{AgNPs}$ and $\mathrm{AgNO}_{3}$. In both of these earlier studies, no effects were observed on survival or growth at Ag concentrations either higher than or overlapping with the concentrations used here. However, the studies used coated NPs and only considered short-term effects (two weeks of exposure). Since C. teleta is considered a pollution tolerant species, adapted to live in organically polluted areas, more studies investigating effects of long-term exposure of AgNPs in other sediment-dwelling organisms are needed to improve our understanding of the environmental risks of these contaminants.

\section{Funding sources}

This research did not receive any specific grant from funding agencies in the public, commercial, or not-for-profit sectors.

\section{CRediT authorship contribution statement}

Maria Bille Nielsen: Conceptualization, Data curation, Formal analysis, Investigation, Writing - original draft, Visualization. Janna Vavra: Methodology, Data curation, Writing - review \& editing. Annemette Palmqvist: Conceptualization, Methodology, Formal analysis, Writing - review \& editing. Valery E. Forbes: Conceptualization, Methodology, Resources, Writing - review \& editing.

\section{Declaration of Competing Interest}

The authors declare that they have no known competing financial interests or personal relationships that could have appeared to influence the work reported in this paper.

\section{Acknowledgments}

We thank Marie-Noële Croteau for conducting ICP-MS analyses of sediments and worms.

\section{Supplementary materials}

Supplementary material associated with this article can be found, in the online version, at doi:10.1016/j.aquatox.2021.106046.

\section{References}

Baun, A., Hartmann, N.B., Grieger, K., Kusk, K.O., 2008. Ecotoxicity of engineered nanoparticles to aquatic invertebrates: a brief review and recommendations for future toxicity testing. Ecotoxicology 17 (5), 387-395. https://doi.org/10.1007/ s10646-008-0208-y.

Blake, J.A., Grassle, J.P., Eckelbarger, K.J., 2009. Capitella teleta, a new species designation for the opportunistic and experimental Capitella sp. I, with a review of the literature for confirmed records. Zoosymposia 2 (1), 25-53. https://doi.org/ 10.11646/zoosymposia.2.1.6.

Dai, L., Selck, H., Salvito, D., Forbes, V.E., 2012. Fate and effects of acetyl cedrene in sediments inhabited by different densities of the deposit feeder, Capitella teleta. Environ. Toxicol. Chem. 31 (11), 2639-2646. https://doi.org/10.1002/etc.1991. 
Dai, L., 2012. Toxicity and Bioaccumulation of Silver and Copper Oxide Nanoparticles in Two Deposit feeders, a Polychaete Capitella teleta and a mollusk, Macoma balthica, Compared to Other Metallic Forms. Roskilde University, Denmark, pp. 61-90. Available online. https://forskning.ruc.dk/en/publications/toxicity-and-bio accumulation-of-silver-and-copper-oxide-nanoparti (accessed 4 March 2021)

Diegoli, S., Manciulea, A.L., Begum, S., Jones, I.P., Lead, J.R., Preece, J.A., 2008. Interaction between manufactured gold nanoparticles and naturally occurring organic macromolecules. Sci. Total Environ. 402 (1), 51-61.

Ellis, L.J.A., Valsami-Jones, E., Lead, J.R., Baalousha, M., 2016. Impact of surface coating and environmental conditions on the fate and transport of silver nanoparticles in the aquatic environment. Sci. Total Environ. 568, 95-106. https://doi.org/10.1016/j. scitotenv. 2016.05.199. Available from.

Gottschalk, F., Lassen, C., Kjoelholt, J., Christensen, F., Nowack, B., 2015. Modeling flows and concentrations of nine engineered nanomaterials in the Danish environment. Int. J. Environ. Res. Public Health 12 (5), 5581-5602.

Hansen, S.F., Heggelund, L.R., Revilla Besora, P., Mackevica, A., Boldrin, A., Baun, A, 2016. Nanoproducts - What is actually available to European consumers? Environ. Sci. Nano 3 (1), 169-180.

Hansen, S.F., Hansen, O.F.H., Nielsen, M.B., 2020. Advances and challenges towards consumerization of nanomaterials. Nat. Nanotechnol. 15 (12), 964-965. https://doi. org/10.1038/s41565-020-00819-7 [Internet]Available from.

Hernández, D., Vidal, J.C., Laborda, F., Pérez-Arantegui, J., Giménez-Ingalaturre, A.C., Castillo, J.R., 2021. Detection, size characterization and quantification of silver nanoparticles in consumer products by particle collision coulometry. Microchim. Acta 188 (1).

Johari, S.A., Sarkheil, M., Behzadi Tayemeh, M., Veisi, S, 2018. Influence of salinity on the toxicity of silver nanoparticles (AgNPs) and silver nitrate $\left(\mathrm{AgNO}_{3}\right)$ in halophilic microalgae, Dunaliella salina. Chemosphere 209, 156-162. https://doi.org/ 10.1016/j.chemosphere.2018.06.098. Available from.

Lopez, G.R., Levinton, J.S., 1987. Ecology of deposit-feeding animals in marine sediments. Q. Rev. Biol. 62 (3), 235-260.

Luo, X., Xu, S., Yang, Y., Li, L., Chen, S., Xu, A., 2016. Insights into the ecotoxicity of silver nanoparticles transferred from escherichia coli to caenorhabditis elegans. Sci. Rep. 1-12. June.

Rajkumar, K.S., Kanipandian, N., Thirumurugan, R., 2016. Toxicity assessment on haemotology, biochemical and histopathological alterations of silver nanoparticles- exposed freshwater fish Labeo rohita. Appl. Nanosci. 6 (1), 19-29. https://doi.org/ 10.1007/s13204-015-0417-, 7.

Ramskov, T., Forbes, V.E., Gilliland, D., Selck, H., 2015. Accumulation and effects of sediment-associated silver nanoparticles to sediment-dwelling invertebrates. Aquatic. Toxicol. 166, 96-105. https://doi.org/10.1016/j.aquatox.2015.07.002.

Ramskov, T., Selck, H., Salvito, D., Forbes, V.E., 2009. Individual- and population-level effects of the synthetic musk, HHCB, on the deposit-feeding polychaete, capitella Sp. I. pharmaceuticals and personal care products in the. Environ. Toxicol. Chem. 28 (12), 2695-2705.

Ramskov, T., Forbes, V.E., 2008. Life history and population dynamics of the opportunistic polychaete Capitella sp. I in relation to sediment organic matter. Mar. Ecol. Prog. Ser. 369, 181-192. https://doi.org/10.3354/meps07584.

Ribeiro, M.J., Maria, V.L., Scott-Fordsmand, J.J., Amorim, M.J.B., 2015. Oxidative stress mechanisms caused by Ag nanoparticles (NM300K) are different from those of AgNO3: effects in the soil invertebrate Enchytraeus Crypticus. Int. J. Environ. Res. Public Health 12 (8), 9589-9602.

Selck, H., Forbes, V.E., Forbes, T.L., 1998. Toxicity and toxicokinetics of cadmium in Capitella sp. I: relative importance of water and sediment as routes of cadmium uptake. Mar. Ecol. Prog. Ser. 164, 167-178. https://doi.org/10.3354/meps164167.

Sun, T.Y., Gottschalk, F., Hungerbühler, K., Nowack, B., 2014. Comprehensive probabilistic modelling of environmental emissions of engineered nanomaterials. Environ. Pollut. 185, 69-76. https://doi.org/10.1016/j.envpol.2013.10.004. Available from.

Sun, T.Y., Bornhöft, N.A., Hungerbühler, K., Nowack, B., 2016. Dynamic probabilistic modeling of environmental emissions of engineered nanomaterials. Environ. Sci. Technol. 50 (9), 4701-4711.

US Environmental Protection Agency, 2001. Methods For Collection, Storage and Manipulation of Sediments for Chemical and Toxicological Analyses; Technical Manual. EPA 823-B-01-002.U.S Environmental Protection Agency, Office of Water, Washington, DC. Available online. https://www.epa.gov/sites/default/files /2015-09/documents/collectionmanual.pdf (accessed 4 March 2021).

Zhao, G., Wang, Z.Y., Xu, L., Xia, C.X., Liu, J.X., 2019. Silver nanoparticles induce abnormal touch responses by damaging neural circuits in zebrafish embryos. Chemosphere 229, 169-180. https://doi.org/10.1016/j.chemosphere.2019.04.223. Available from. 